\title{
Balance velocities and measured properties of the Antarctic ice sheet from a new compilation of gridded data for modelling
}

\author{
Philippe Huybreghts, ${ }^{1}$ Daniel Steinhage, ${ }^{1}$ Frank Wilhelms, ${ }^{1}$ Jonathan Bamber ${ }^{2}$ \\ ${ }^{1}$ Alfred-Wegener-Institut für Polar-und Meeresforschung, Postfach 120161, D-27515 Bremerhaven, Germany \\ ${ }^{2}$ Bristol Glaciology Centre, School of Geographical Sciences, University of Bristol, Bristol BS8 1SS, England
}

\begin{abstract}
This paper presents a new compilation of gridded datasets for threedimensional modelling of the Antarctic ice sheet. These are for surface elevation, ice thickness, bedrock elevation and accumulation rate as interpolated on a $281 \times 281$ mesh with $20 \mathrm{~km}$ spacing, and encompass all the ice sheet and surrounding continental shelf. Data sources include the Bamber digital-elevation model from ERS-1 radar-altimeter data, a redigitization of available ice-thickness data, the Giovinetto accumulation data, recent icethickness data from British and German expeditions as well as accumulation data from German and Norwegian expeditions. In particular, new data were incorporated for the Filchner-Ronne Ice Shelf and for Dronning Maud Land, Antarctica, arising from the EPICA pre-site survey. Special attention was devoted to matching the various data sources carefully, both among themselves and across the grounding line and below the ice shelves, to enable ice-sheet expansion and retreat in dynamic situations. As an application, the balance flow is calculated over the entire ice sheet using a two-dimensional finite-difference scheme and compared with a previous assessment. This brought to light the existence of ice-streaming features extending well inland. A detailed zoom over Dronning Maud Land exhibits the general flow characteristics of interest for locating a future deep-drilling site. As a by-product, an updated value of $26.4 \times 10^{6} \mathrm{~km}^{3}$ was obtained for the total volume of the ice sheet and ice shelves, or equivalent to $61.1 \mathrm{~m}$ of global sea-level rise after removal of the ice sheet and subsequent oceanic invasion and isostatic rebound. The total accumulation over the grounded ice sheet, including the Antarctic Peninsula, is $1924 \mathrm{Gt} \mathrm{a}^{-1}$, or between 5 and $20 \%$ higher than earlier estimates. Including all the ice shelves, the value is $2344 \mathrm{Gt} \mathrm{a}^{-1}$.
\end{abstract}

\section{INTRODUGTION}

Accurate numerical modelling of the Antarctic ice sheet requires access to the best available datasets. In large-scale prognostic studies, in which ice thickness and ice-sheet extent are predicted forward in time, bedrock topography and accumulation rate represent the main input fields (e.g. Huybrechts, 1990). In particular, the position of the grounding line and the evolution of the ice shelves are very sensitive to bed elevation and the distribution of sea-bed shoals around the margin of the ice sheet. Similarly, mountain ranges have a strong effect on surface topography because they can dam the ice flow and act as nucleation sites in studies concentrating on the growth of the ice sheet in former geological times (Barker and others, 1999). The depth of troughs into which the ice is channelled at the margin is equally important as it determines the ice flux and therefore affects the configuration and surface topography of the catchment area. In addition, bedrock depth below the surface provides an important control for basal temperature because of the insulation effect of the ice, and thus regulates processes such as basal melting, basal sliding and basal-water flow.

In diagnostic studies, high accuracy is required for the key boundary conditions of surface elevation and ice thickness. On length scales an order of magnitude larger than ice thickness, driving stress is proportional to the product of sur- face slope and ice thickness. However, due to the non-linearity of the flow law, small errors in these are strongly amplified when calculating the locally defined "dynamics velocity" (e.g. Bamber and others, 2000). Together with the accumulation rate, ice thickness and surface slope also determine the pattern of "balance velocity" which, compared with the modelderived "dynamics velocity", may help to constrain uncertainties introduced by the flow law, the ice viscosity (as a function of ice temperature and crystal properties) and/or basal sliding. Comparison of balance velocities with observations may also shed more light on the crucial problem of ice-sheet evolution and the response to global environmental changes.

So far, virtually all large-scale modelling studies of the Antarctic ice sheet relied on gridded versions of the Scott Polar Research Institute (SPRI) glaciological and geophysical folio (Drewry, 1983), originally digitized by the Australian group (Budd and others, 1984) on a $20 \times 20 \mathrm{~km}$ grid, and generalized on a $40 \mathrm{~km}$ grid with slight adaptations afterwards (Huybrechts, 1990; EISMINT Intercomparison Project, http: //homepages.vub.ac.be/ phuybrec/eismint/antarctica.html). However, as discussed in detail by Bamber and Huybrechts (1996), substantial deficiencies were found in these geometric datasets, due to combinations of errors and inconsistencies in the folio maps, errors in the digitization, and significant differences between the surface-elevation distribution of the 
SPRI map and a much improved elevation model derived from European Remote-sensing Satellite (ERS-1) radar-altimeter data. Perhaps most remarkably, the total ice volume mentioned in Drewry and others (1983), and widely quoted since, was about $12 \%$ larger than the value derived from a direct digitization of the corresponding thickness map of the folio, which in turn differed from the distribution derived separately by subtracting bed elevation from surface elevation, as was done in the Budd digitization. An unequivocal explanation for these mismatches could not, however, be established, and definite answers should perhaps await the results of a future comprehensive recompilation of all Antarctic data as part of the BEDMAP Project (Vaughan, 1996; http: //www. nerc-bas.ac.uk/public/aedc/bedmap/bedmap.html).

The Bamber and Huybrechts (1996) grids were restricted to grounded ice only and excluded the Antarctic Peninsula, limiting the scope of their application. In this paper, we build further on these datasets and extend the grids beyond their current limits to include all of the continental shelf and surrounding ocean. At the same time, we develop a new gridded dataset for accumulation rate over the same model domain. The direct stimulus for undertaking this work is related to forthcoming detailed model studies of ice-sheet dynamics in Dronning Maud Land (DML), Antarctica, within the framework of the European Project for Ice Coring in Antarctica (EPICA) and the planned retrieval of a deep ice core. Therefore, special attention was devoted to incorporating all new data collected as part of the EPICA pre-site survey, most notably by the Alfred Wegener Institute (Steinhage and others, 1999; Oerter and others, 1999, 2000). Furthermore, it proved useful to reconsider data throughout Antarctica because the flow dynamics of DML is difficult to separate from changes occurring elsewhere on the ice sheet, especially when the interest is in the glacial cycles.

The consistency and quality of the new gridded datasets are demonstrated with a new assessment of the vertically integrated flow required for steady state (balance flow). In addition, an enlarged map of balance velocity over DML shows the flow activity of interest for siting a future ice core. At the same time, updated numbers on the size and the surface mass balance of the Antarctic ice sheet are provided.

\section{SPECIFICATIONS FOR MODELING PURPOSES}

The equations of the ice-sheet-ice-shelf model are solved with the finite-difference method. This requires the data to be specified on a Cartesian grid with rectangular boundaries. Because the ice sheet must be able to expand and retreat, the domain needs to cover all Antarctica and its surrounding continental shelf. In particular, the sea-bed elevation needs to be specified below the ice shelves and match the bed topography below the grounded ice sheet fluently. The most crucial area is close to the grounding line, where all three parameters, surface elevation, bed elevation, and ice thickness need to be consistent with a specified flotation criterion to predict regions of grounded and floating ice correctly. A further requirement is that the data need to be continuous over all the grid. In particular, there should be no gaps or nunataks sticking out of the ice sheet because these are difficult to handle, especially in dynamic situations.

For simplicity, we opted for the same $281 \times 281$ grid with $20 \mathrm{~km}$ constant spacing of the Budd datasets. The map projection is polar stereographic with a standard parallel at $71^{\circ} \mathrm{S}$ as adopted for the SPRI map folio. This projection conserves directions, but on the other hand is characterized by non-negligible areal distortions ranging from $-8 \%$ at $60^{\circ} \mathrm{S}$ to $+5.6 \%$ at the South Pole: more optimal alternatives exist, but were not attempted for reasons of consistency with previous datasets.

\section{DATA SOURGES}

\section{Surface elevation}

Over most of the ice sheet and the surrounding shelf, the surface-elevation dataset consisted of a filtered $20 \mathrm{~km}$ version of the surface data presented by Bamber and Huybrechts (1996). For most of the continent, this digital-elevation model was derived from more than 20 million measurements of surface elevation retrieved from eight 35 day repeat cycles of ERS-1 satellite radar-altimeter data. Over areas where slopes are $<0.4^{\circ}$, the vertical accuracy is better than $\pm 1.5 \mathrm{~m}$. Accuracy is reduced in areas of higher slope. Around the coast and in mountainous areas where the altimeter failed to maintain track on the ice-sheet surface, the altimeter measurements were supplemented with data taken from the Antarctic digital database (ADD) (Thomson and Cooper, 1993). Beyond the orbital limit of ERS-1 (south of $81.5^{\circ} \mathrm{S}$ ), the data were merged with those from the SPRI map folio series (Drewry, 1983) and the transition smoothed. Over Graham Land and the adjacent part of Palmer Land (Antarctic Peninsula), data from the Budd grids were used. All surface elevations are referenced to the OSU91a geopotential model.

Surface slopes and flow directions were calculated (not shown) to check whether the transitions between the different data sources were smooth and continuous. This turned out to be the case despite the apparent difference in texture of the shaded-relief map shown in Bamber and Huybrechts (1996) for the area south of $81.5^{\circ} \mathrm{S}$, and is probably in part a consequence of the additional smoothing introduced by the filtering from a $10 \mathrm{~km}$ to a $20 \mathrm{~km}$ grid. Such additional smoothing is also in agreement with the theory which requires surface slopes to be averaged over at least 5-10 ice thicknesses to be representative of the large-scale flow.

\section{Ice thickness}

The basic dataset for ice thickness also originated from a filtered $20 \mathrm{~km}$ version of the corresponding Bamber and Huybrechts (1996) data. This dataset was produced from a combination of a redigitization of the SPRI thickness map and the original radio-echo-sounding flight lines, where they were present. The data were amended in three areas: DML, the Filchner-Ronne basin and the Antarctic Peninsula.

The DML data primarily arose from the EPICA pre-site survey conducted by the Alfred Wegener Institute (Steinhage and others, 1999). From 1995-97, more than $49500 \mathrm{~km}$ of airborne radio-echo soundings (RES) were obtained covering a hitherto uncharted area of $948000 \mathrm{~km}^{2}, 25^{\circ} \mathrm{W}$ to $20^{\circ} \mathrm{E}$, and $72^{\circ}$ to $80^{\circ} \mathrm{S}$. Additional RES data were provided by the British Antarctic Survey for the area between $0^{\circ}$ and $8^{\circ} \mathrm{W}$ and $74^{\circ}$ and $76^{\circ} \mathrm{S}$ (personal communication from D. G. Vaughan, 1997).

For the Filchner-Ronne Ice Shelf area, a different strategy was followed. Here, ice thickness was calculated from the bed topography and the depth of the water column below the ice shelf as given by Vaughan and others (1995; http://www.nerc-bas.ac.uk/public/icd/dgv/) and subsequently 
transformed into ice thickness by applying the flotation criterion. Throughout this paper, the flotation criterion uses fixed densities of $910 \mathrm{~kg} \mathrm{~m}^{-3}$ and $1028 \mathrm{~kg} \mathrm{~m}^{-3}$ for ice and ocean water, respectively. Data for the Antarctic Peninsula north of $60^{\circ} \mathrm{S}$ were merged from the Budd digitization, though these required substantial manual editing (cf. section 4 ).

\section{Bed elevation}

Bed elevation below the grounded ice sheet was recalculated from the difference between surface elevation and ice thickness to ensure consistency. Outside the grounded-ice limit, the Budd digitization was used, except for the FilchnerRonne area where the data came from Vaughan and others (1995).

\section{Accumulation rate}

The accumulation rate over most of the Antarctic ice sheet was interpolated from the latest update of the Giovinetto and Bentley (1985) dataset. Net surface-balance values were provided as areal means of 1351 gridcells of $100 \times 100 \mathrm{~km}$ all over the ice sheet and the ice shelves, except for the Antarctic Peninsula (personal communication from M. B. Giovinetto, 1997). Outside this domain, precipitation climatologies were employed which are used to initiate high-resolution general circulation models as well as a compilation of 20 point measurements of the Antarctic Peninsula (personal communication from D. G. Vaughan, 1998; http://www.nerc-bas.ac.uk/ public/icd/dgv/).

The combined dataset was then used as a background forcing field to control the incorporation of new point measurements of mean annual accumulation obtained from the EPICA pre-site survey. These included 17 measurements along a traverse from Neumayer station to the Kottas Mountains, 10 new data points on Amundsenisen from the 1995/96 and 1996/97 seasons (Oerter and others, 1999), supplemented by a further 14 data points in the same area from the season 1997/98 (Oerter and others, 2000). These data were mainly derived from shallow firn cores, many of which go back at least 100 years. Dating was by identifying the 1964-65 Agung sulfate horizon, the 1810-16 double peak representing the 1815 Tambora eruption and an additional unknown event in 1809. Gamma-absorption ice densities were measured with a scintillation detector mounted on the same automatic core-analysis bench used to measure conductivity (Wilhelms and others, 1998). The accumulation rates thus represent an average over the last 100 200 years and are believed to have a remaining error of less than $1 \mathrm{~cm} \mathrm{a}^{-1}$.

An additional 12 data points were provided by the Norwegian traverse inland from Troll station during the 1996/97 season (Van den Broeke and others, 1999).

\section{DATA MANIPULATION}

For interpolating the data, extensive use was made of the continuous-curvature spline-algorithm "surface" with a tension factor of zero (minimum curvature), available as part of the GMT software (Smith and Wessel, 1990). This is equivalent to a low-pass filter with smoothing characteristics well suited to avoid numerical instabilities in the numerical model.

Updated subsets of ice-thickness and bed-topography data were merged within the main dataset by calculating the height offset at the common boundary and using this to weight the main dataset as a function of distance from this boundary. A distance-cubed weighting was found to provide smooth transitions and continuity of slope across the boundaries. Accumulation point measurements were given a weighting factor of 10, compared to the background Giovinetto data, to control the interpolation between the irregularly and sparsely distributed measurements. At the grid margin, a fixed value of $0.5 \mathrm{~m} \mathrm{a}^{-1}$ was adopted. This has no influence on values within the possible maximum extent of the Antarctic ice sheet, but ensures that the flow velocities in the surrounding ice shelf, which extends to the grid margin, do not give rise to numerical instabilities.

To satisfy the peculiarities of the numerical model and its parameterizations (Huybrechts, 1990), some small editing of the resulting datasets was necessary. These concerned local corrections that would not falsify any large-scale characteristics of the Antarctic ice sheet, but are required to avoid spurious, unwanted, or unrealistic effects in the model.

Manual intervention was needed to remove a rock barrier, running from Mawson Escarpment to the Prince Charles Mountains, which would have dammed the flow at the head of Lambert Glacier, but is in reality a collection of nunataks rather than a continuous mountain range. Editing of geometric data was also necessary in the Peninsula area to float the Larsen and George VI Ice Shelves. For these parts, no data existed on the SPRI thickness folio, justifying the manual intervention. Ice thickness was also set at the minimum value of $10 \mathrm{~m}$ over rock outcrops.

The treatment of the mass balance in the ice-sheet model assumes that the data for net surface mass balance, as a result of snowfall, hoarfrost, sublimation, melting, wind scouring, drift-snow deposition, etc., can be equated to precipitation. Runoff, or the fraction of precipitation falling as rain, if any, is derived in the model from the precipitation rate (Huybrechts and de Wolde, 1999). Precipitation rates for different climates are then calculated as proportional to the gradient of the saturated water-vapor pressure at the temperature above the surface inversion layer (Robin, 1977). While probably being a reasonable first-order estimate, especially over most of the plateau area, the calculation requires positive input data. Zero or negative accumulation points have therefore been re-interpolated from surrounding positive gridpoints. The minimum value was set at $15 \mathrm{~mm} \mathrm{a}^{-1}$. This effectively removed the blue-ice areas such as the area with negative mass balance at the head of Lambert Glacier, whose existence has otherwise been questioned (Allison and others, 1985).

\section{RESULTS}

Figure 1 shows the four new gridded datasets for bedrock elevation, ice thickness, surface elevation, and accumulation rate. Their principal feature is the complete coverage and improved detail in DML and on the Filchner-Ronne Ice Shelf as compared to the older SPRI maps. Over much of the continent, the geometric datasets are equivalent to those discussed by Bamber and Huybrechts (1996) and so are the improvements with respect to the Budd grids. Important new bedrock features, not seen on the SPRI map folio, include the deep subglacial troughs below Bailey Ice Stream and Slessor Glacier that extend well inland, as well as the rough mountainous terrain below DML (Steinhage and others, 1999). Improvements in the accumulation grid also involve 
Huybrechts and others: Balance velocities and properties of the Antarctic ice sheet

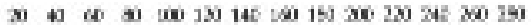
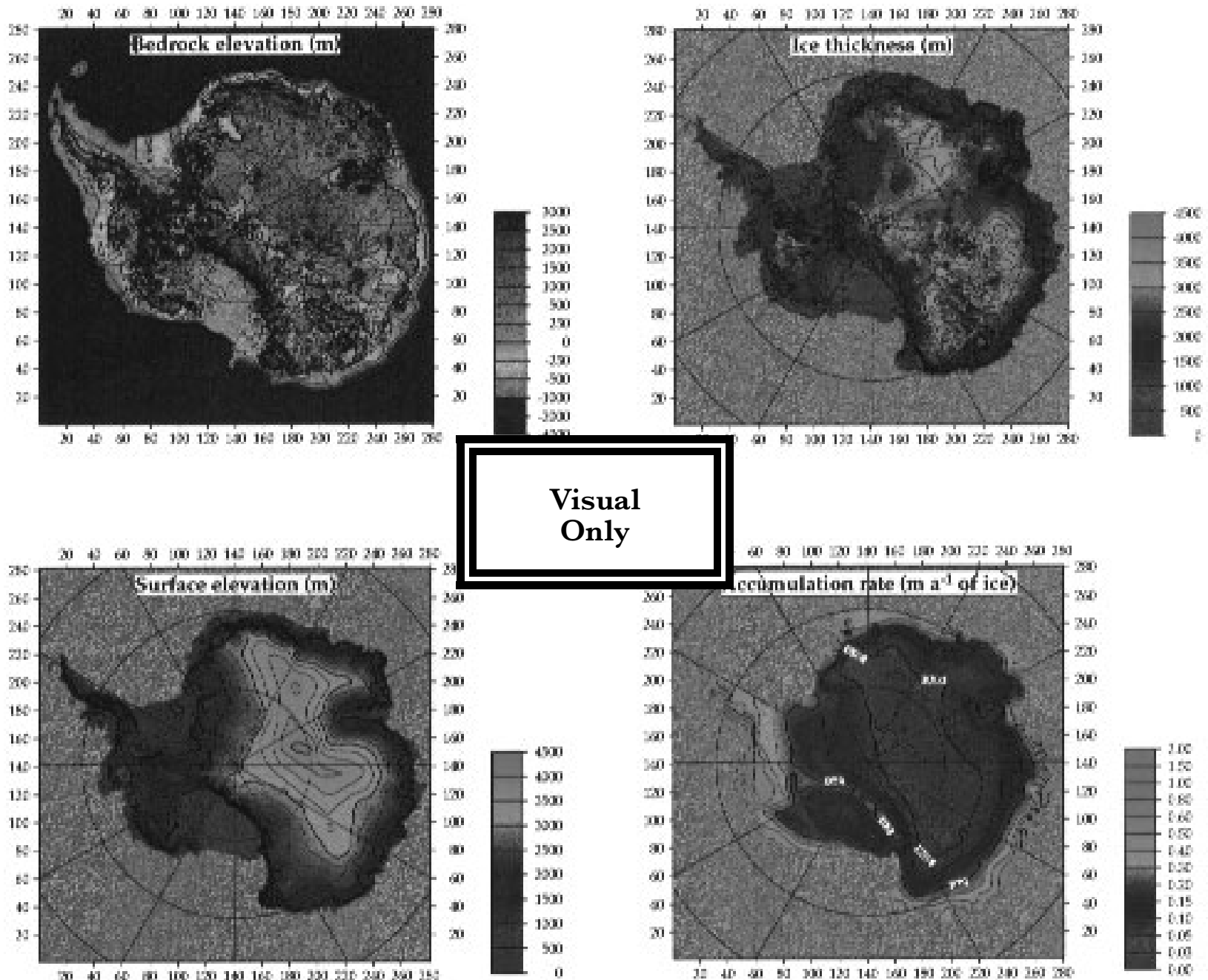

Visua
Only

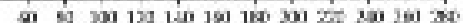

Fig. 1. Contoured representations of the new datasets for ice-sheet modelling as developed in this study. Except for bed elevation, they are displayed within the area of the conterminous Antarctica, although all parameters are defined within the entire grid square. The bold line in the bedrock plot is for 0 m a.s.l.

$\begin{array}{llllllllllllllll}20 & 40 & 60 & 80 & 100 & 120 & 140 & 160 & 180 & 200 & 220 & 240 & 260 & 280\end{array}$
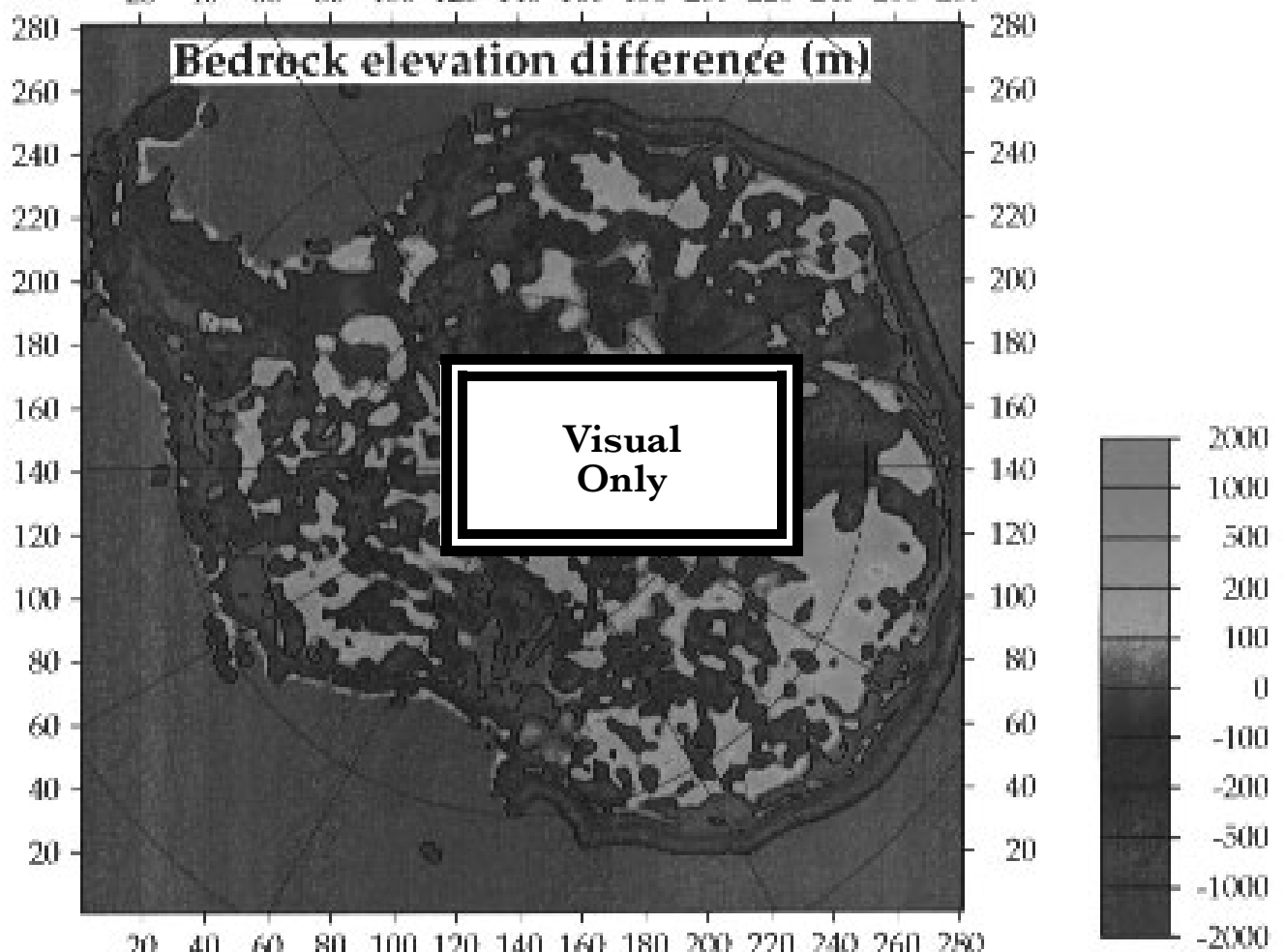

Fig. 2. Differences between the bedrock dataset of this paper and the bed grid digitized from the SPRI folio (Drewry, 1983) by Budd and others (1984). A negative difference means that the bed in the Budd dataset lies above ours. The $0 \mathrm{~m}$ contour is shown in bold. 
Table 1. Comparison of measured properties of the Antarctic ice sheet

\begin{tabular}{|c|c|c|c|}
\hline Parameter & Drewry and others (1982) & Huybrechts $(1990)^{\mathrm{a}}$ & This paper \\
\hline \multicolumn{4}{|l|}{ Area $\left(10^{12} \mathrm{~m}^{2}\right)$} \\
\hline Grounded ice sheet & $12.045(86.6 \%)$ & $12.974(88.7 \%)$ & $12.370(88.5 \%)$ \\
\hline Ice shelves & $1.542(11.0 \%)$ & $1.649(11.3 \%)$ & $1.486(10.6 \%)$ \\
\hline All ice sheet & $13.586(97.6 \%)$ & $14.623(100 \%)$ & $13.856(99.1 \%)$ \\
\hline Ice-free terrain (rock) & $0.332(2.4 \%)$ & 0 & $0.128(0.9 \%)$ \\
\hline \multicolumn{4}{|l|}{ Ice volume $\left(10^{15} \mathrm{~m}^{3}\right)$} \\
\hline Conterminous Antarctica & $30.110(100 \%)$ & $25.386(100 \%)$ & $26.373(100 \%)$ \\
\hline Grounded ice & $29.378(97.6 \%)$ & $24.719(97.4 \%)$ & $25.715(97.5 \%)$ \\
\hline Ice shelves & $0.732(2.4 \%)$ & $0.667(2.6 \%)$ & $0.658(2.5 \%)$ \\
\hline \multicolumn{4}{|l|}{ Mean ice thickness ( $m$ ) } \\
\hline Conterminous Antarctica & 2160 & 1735.9 & 1903.2 \\
\hline Grounded ice sheet & 2450 & 1905.2 & 2078.7 \\
\hline Ice shelves & 475 & 404.3 & 442.7 \\
\hline \multicolumn{4}{|l|}{ Mean bed elevation $(m)^{\mathrm{b}}$} \\
\hline All continent & -160 & 70.4 & 50.3 \\
\hline Grounded ice sheet & & 163.5 & 134.4 \\
\hline Sea-level equivalent $(m)^{c}$ & & 58.49 & 61.14 \\
\hline \multicolumn{4}{|c|}{ Accumulation $\left(10^{9} \mathrm{~m}^{3} a^{-1}\right.$ ice equivalent $)$} \\
\hline Conterminous Antarctica & & $2886.1(100 \%)$ & $2576.2(100 \%)$ \\
\hline Grounded ice & & $2393.1(82.9 \%)$ & $2115.4(82.1 \%)$ \\
\hline Ice shelves & & $493.0(17.1 \%)$ & $460.8(17.9 \%)$ \\
\hline \multicolumn{4}{|c|}{ Mean accumulation rate ( $m a^{-1}$ ice equivalent) } \\
\hline Conterminous Antarctica & & 0.197 & 0.186 \\
\hline Grounded ice & & 0.184 & 0.171 \\
\hline Ice shelves & & 0.299 & 0.310 \\
\hline
\end{tabular}

Notes: The gridsize is $40 \mathrm{~km}$ for the Huybrechts (1990) data and $20 \mathrm{~km}$ for this paper. Data from Huybrechts (1990) and this paper all take into account areal corrections for the map projection, which makes the Antarctic ice sheet about $2.3 \%$ larger than for a Cartesian grid with a fixed mesh size. Integrations and average values of ice volume, ice thickness and accumulation rate exclude rock outcrops.

(a) Data originate from the Budd digitization (Budd and others, 1984) of the Drewry (1983) map folio series and from an interpolation of the SPRI accumulationrate dataset (personal communication from A. P. R. Cooper, 1986).

(b) Data from Huybrechts (1990) and this paper are for the continent defined above the $-3000 \mathrm{~m}$ contour; the definition for Drewry (1982) is not entirely clear.

(c) This value takes into account the effects of sea water replacing the ice load and of subsequent isostatic rebound with an ice-rock density ratio of 0.275 ; the oceanic area was fixed at $3.62 \times 108 \mathrm{~km}^{2}$, or $71 \%$ of the Earth's surface.

more detail in DML where the transition to a desertic precipitation regime (as defined by the $0.05 \mathrm{~m} \mathrm{a}^{-1}$ contour) is now more inland than in previous compilations.

A map of bed-elevation differences with the Budd grids summarizes some of the progress made in the last 15 years (Fig. 2). Over much of Wilkes Land, the bed is more than $500 \mathrm{~m}$ higher than in the Budd grids, which was attributed to a combination of errors in the surface-elevation data and the original digitization of the folio maps (Bamber and Huybrechts, 1996). In DML, the new bedrock topography is generally higher (and the ice thinner) east of the Greenwich meridian by up to $1000 \mathrm{~m}$, while the reverse is evident in the western part of DML. Important differences can also be seen in the Filchner-Ronne basin, reflecting the vast increase in measurements since the SPRI folio was published in 1983.

A comparison of measured properties with earlier assessments of the Antarctic ice sheet is shown inTable 1. Most strikingly, the substantial reduction of ice volume by about $12 \%$ compared to the Drewry and others (1982) figure is confirmed. Despite the inclusion of the Antarctic Peninsula, the present value for total ice volume (ice sheet and ice shelves) of $26.37 \times 10^{6} \mathrm{~km}^{3}$ is about $1 \%$ lower than the value found in Bamber and Huybrechts (1996), which is mainly due to the higher topography of DML. On the other hand, we find comparably small differences with the Drewry and others (1982) figures for areal statistics. There is an even closer agreement (within 0.2\%) with the Fox and Cooper (1994) update based on the Scientific Committee on Antarctic Research ADD, though the position of the grounding line, especially along the Siple Coast and around Graham Land, is somewhat different. This is to be expected because of the difficulties of locating the grounding line at the mouth of ice streams where surface slopes are low and the usual strong break in slope is not well-developed. We find a reduction in the area of ice-free terrain to about a third of the Drewry and others (1982) figure, but our value is still three times larger than the figure derived in the Fox and Cooper (1994) analysis. Our result here is biased by the minimum pixel size of $20 \times 20 \mathrm{~km}$ and the absence of rock outcrops in the Antarctic Peninsula.

Total accumulation over the conterminous grounded ice sheet is more than $25 \%$ higher than the earlier Giovinetto and Bentley (1985) estimate. On the other hand, we find a value which is only slightly higher $(+2.5 \%)$ than a recent independent compilation by Vaughan and others (1999) when including the ice shelves. This reduction in the spread of estimates seems to reflect the progress made towards a greater consensus on the total yearly mass input of the Antarctic ice sheet. Some of the differences with the Vaughan and others (1999) figure are likely due to a slightly different delineation of the ice sheet and a different control field, whereas the removal of ablation islands in our dataset hardly influences the result at all. 
$\begin{array}{llllllllllllll}20 & 40 & 60 & 80 & 100 & 120 & 140 & 160 & 180 & 200 & 220 & 240 & 260 & 280\end{array}$

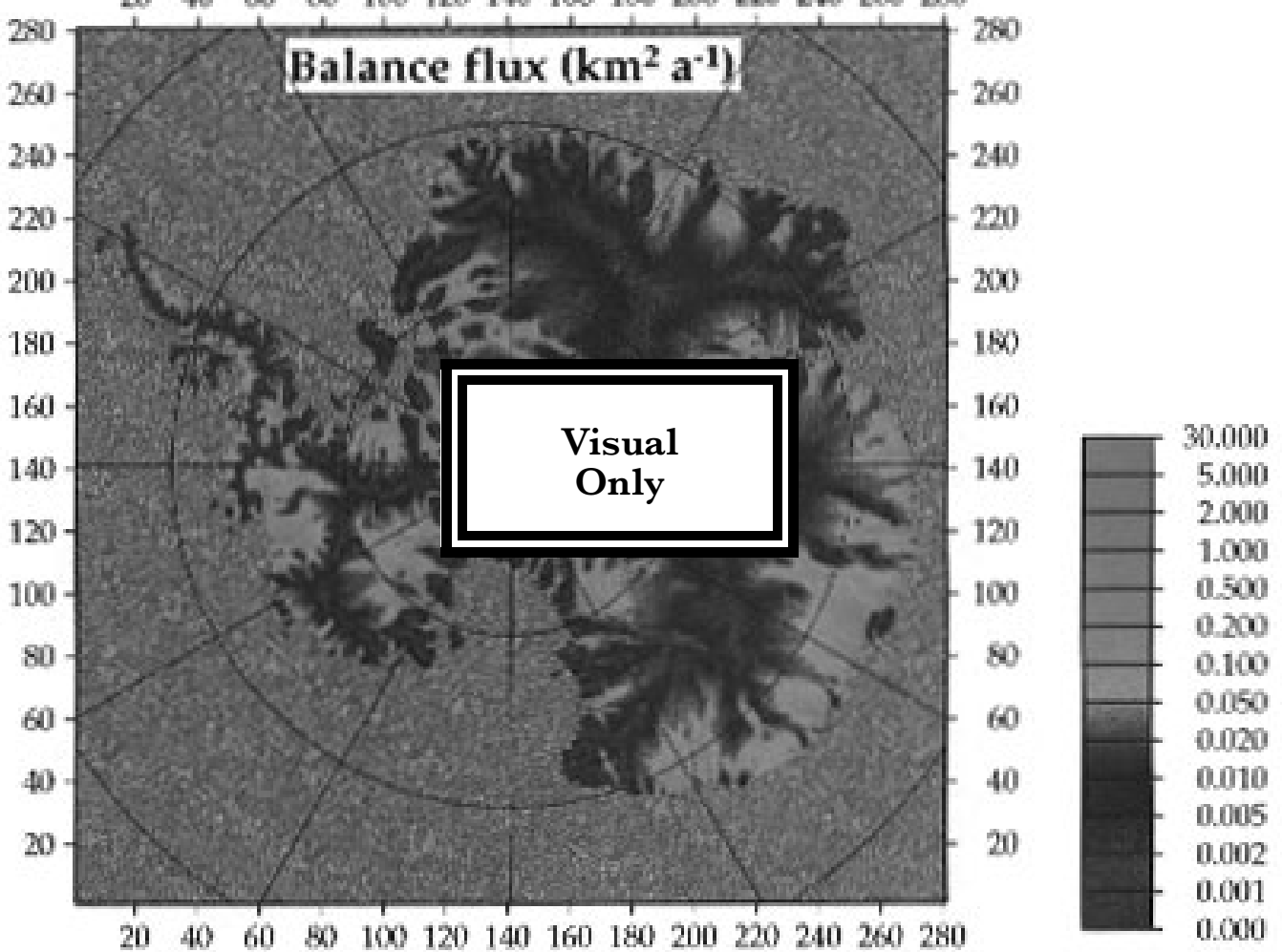

Fig. 3. The pattern of ice-balance flux over the grounded ice sheet in units of the transport quantity $\mathrm{km}^{2} \mathrm{a}^{-1}$. The pattern over the ice shelves is not shown because the flow is not necessarily parallel to the aspect as assumed by the method.

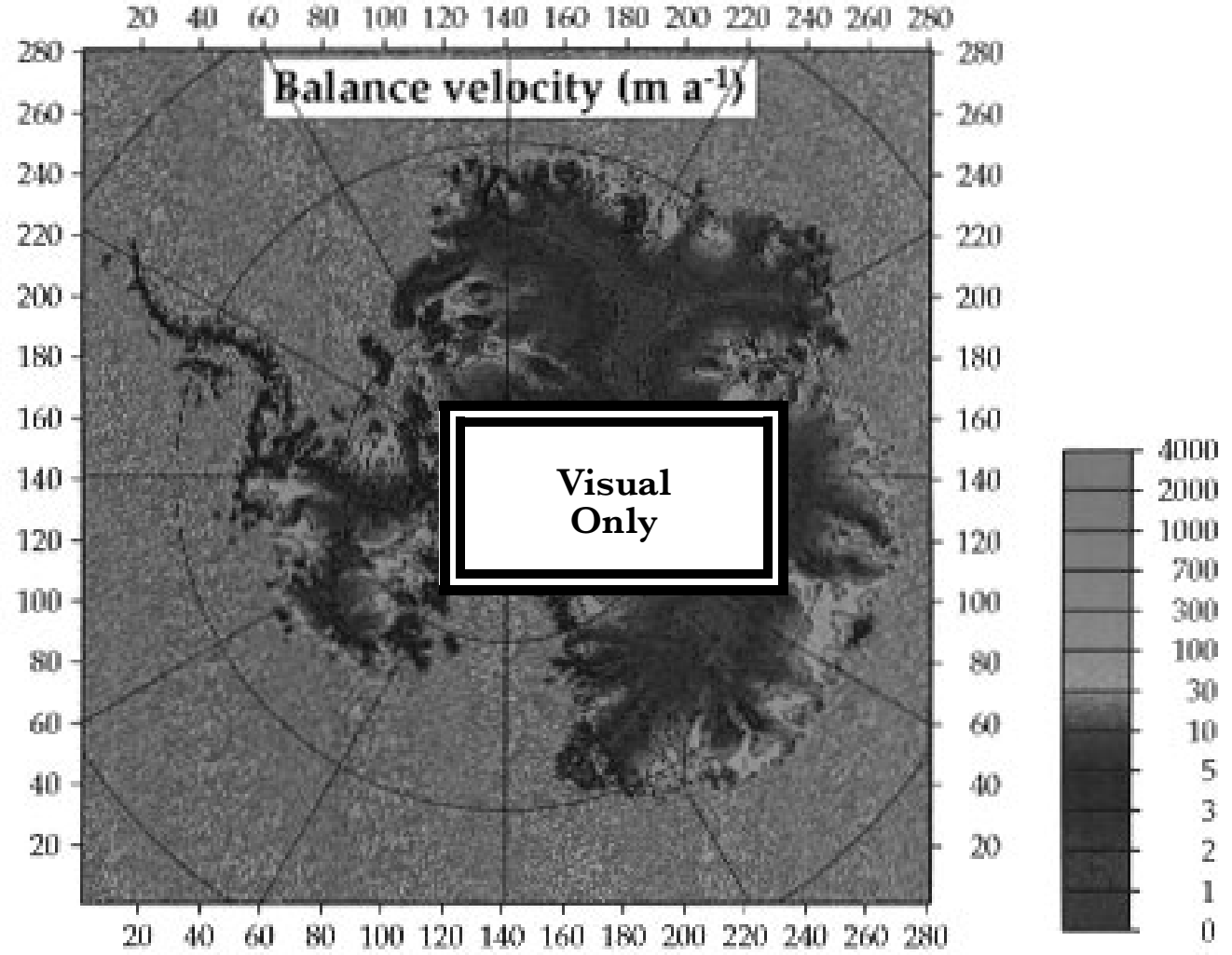

Fig. 4. Balance velocities over the Antarctic ice sheet obtained by dividing the balance flux shown in Figure 3 by the local ice thickness. The data allow for fine detail and resolve all of the major ice streams and outlet glaciers discharging from the grounded ice sheet. 


\section{Balance velocity $\left(\mathrm{m} \mathrm{a}^{-1}\right)$}
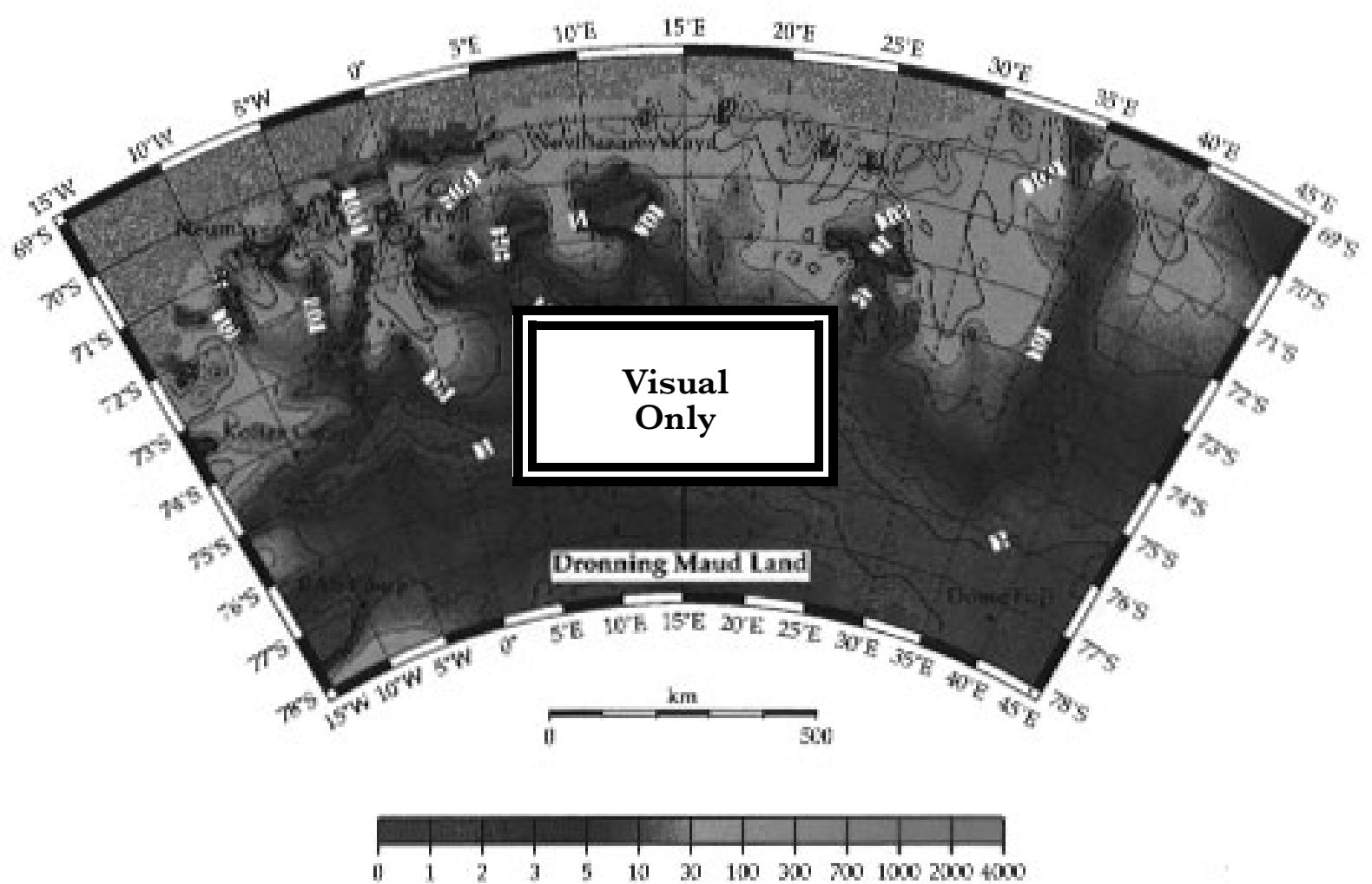

Fig. 5. Zoom of the balance-velocity pattern over Dronning Maud Land. These results represent column-averaged values, and should be multiplied by a factor between 1 and 1.15 for comparison with surface-velocity determinations. Bold lines are for the 1, 10,100 , and $1000 \mathrm{~m} \mathrm{a}^{-1}$ contours.

\section{BALANGE FLOW}

A calculation of balance fluxes and balance velocities provides an excellent illustration of the quality of the datasets and, moreover, yields a good insight in the general flow pattern of the Antarctic ice sheet. While such a calculation only produces an estimate of the vertically averaged flow required to maintain continuity, it shows very well where the flow is converging into streams and where ice divides and drainage boundaries are located.

The balance flow was calculated with the two-dimensional finite-difference method described by Budd and Warner (1996), amended to take into account areal distortions introduced by the map projection. As input, surface-elevation, ice-thickness, and accumulation-rate data are required, which were supplemented by a mask file in order to exclude the ice-free land and the ice shelves. The main assumption underlying the method is that the flow is in the direction of steepest descent, as calculated over a representative distance of about 10 ice thicknesses. The method further requires that no surface hollows or exactly flat regions exist. Such areas were first removed by setting them equal to the average of the surrounding gridpoints. Corrections were necessary for about a thousand points, most of which were around rock outcrops or near to the grounding line. The only major depression in the surface data was found near Hercules Dome $\left(\approx 86^{\circ} \mathrm{S}, 115^{\circ} \mathrm{W}\right)$. The correction procedure for calculating the balance flow involved elevation changes by a few hundred metres at most which were hardly detectable on the scale of the plots, but are excluded from the datasets in Figure 1.

The resulting balance flux is shown in Figure 3. A lot of fine detail can be seen, which primarily results from the elevation model, and to a lesser extent from the accumulation data. A dendritic pattern of major flow paths can be traced well inland. All major outlet glaciers and ice streams, in both East and West Antarctica, are clearly visible. That is particularly the case for the Siple Coast Ice Streams A to E, but Pine Island Glacier, Rutford Ice Stream, Foundation Ice Stream, Support Force Glacier, Recovery Glacier, Slessor Glacier, Jutulstraumen, Lambert and Byrd Glaciers also exhibit strongly convergent flow and fluxes in excess of $0.5 \mathrm{~km}^{2} \mathrm{a}^{-1}$.

A clearly noticeable feature is Lake Vostok $\left(\approx 78^{\circ} \mathrm{S}\right.$, $105^{\circ} \mathrm{E}$ ), where the ice is predicted to be channelled in a southerly direction parallel to the maximum surface slope over the lake. This is, however, an area where the model assumptions are likely to break down. It is more probable that the flow over the lake is driven by ice velocities and strain rates around the lake margin rather than by the local surface slope, which trends north-south, or by the local strain rate which is similar to the dynamics of a confined ice shelf. Consequently, it is plausible that the general flow would not greatly change direction and magnitude over the lake and would be similar to the flow at its eastern and western sides (personal communication from C. Mayer, 1999). Other subglacial lakes in East Antarctica are only a few kilometres in extent (Siegert and others, 1996) and therefore of subgrid scale and too small to disrupt the general flow pattern. A second unusual feature can be seen in the catchment areas of Foundation Ice Stream and Support Force Glacier, where flowlines appear to run parallel over most of their route down from the South Pole. This appar- 
ently represents a poorly constrained ice divide. A distinct flow channel is also evident upstream of Recovery Glacier, which appears to skirt the $81.5^{\circ} \mathrm{S}$ boundary where the two surface datasets were matched, and therefore is possibly an artifact arising from the surface model. There is a maximum flux well inland, which suggests convergent flow followed by a strong divergence further downstream.

Comparing the pattern of balance flux with the earlier assessment presented in Budd and Warner (1996) demonstrates the effect of the new datasets. The main aspects are a more concentrated flow, less continuous divides and new features such as Lake Vostok and Recovery Glacier. Also the pattern south of $80^{\circ} \mathrm{S}$ is quite different from the earlier calculation, though it is not clear to what extent the poorer data, derived from terrestrial, airborne, and TWERLE balloon measurements, could have played a role here.

Figure 4 shows the corresponding pattern of balance velocity. These are vertically averaged values, which need to be multiplied by the surface-to-column velocity ratio to obtain surface values. This ratio depends mainly on the temperature conditions in the basal layers, and can be shown to vary between about 1.15 for cold basal conditions to close to unity where the base is at the melting point and basal sliding takes place. Large flow velocities, generally in excess of $1 \mathrm{~km} \mathrm{a}^{-1}$, are predicted for the same outlets having large fluxes as mentioned above.

A zoom on DML, where the input data reflect the most recent status of the observations, allows areas of active and stagnant flow of interest for siting the future EPICA ice core to be distinguished (Fig. 5). In order to avoid important problems of interpretation of the climatic signal, in terms of the origin of the ice, it would be preferable to drill in an area where flow velocities are less than a few metres per year at most. Such conditions, for example, are provided in the region around $75^{\circ} \mathrm{S}$ and $0^{\circ} \mathrm{W}$, a saddle area inland of Kottasberge, where ice thickness is $2000-3000 \mathrm{~m}$ and accumulation rates are $<0.1 \mathrm{~m} \mathrm{a}^{-1}$.

\section{CONGLUSIONS}

New high-resolution datasets have been constructed for three-dimensional modelling of the Antarctic ice sheet. These data represent a significant improvement over the boundary conditions available so far as they cover the entire Antarctic continent and include the most up-to-date observations, in particular for Dronning Maud Land.

Here the datasets were used to calculate the balance flow over all the ice sheet, providing an excellent snapshot of the motion of the ice sheet in steady-state. The pattern of balance velocities yielded a surprising wealth of detail. Most remarkably, concentrated flow paths were found to extend well inland, throwing new light on the notion of "sheet flow" generally accepted for large continental ice sheets. Moreover, in many areas, it may be assumed that the balance velocities should be, after correction for the surface-to-column ratio, close to reality as the longer-term imbalance was found to be quite small and below $10 \%$ of the local mass balance over most of the ice sheet (Wingham and others, 1998). Because the surface slopes are believed to be the most accurate, comparison with observed velocities may equally well point to deficiencies in the accumulation and ice-thickness data.

Balance velocities also provide initial conditions for $\mathrm{dy}$ namic ice-sheet models and are very useful for model vali- dation. Comparison with model-derived dynamic velocities furthermore helps to constrain the uncertainties introduced by the flow law, basal sliding and the temperature regime of the ice sheet (Bamber and others, 2000).

In addition, the balance flow helps guide measurements in the field. An enlargement over DML displayed the general flow pattern useful for locating the future EPICA deep ice core; thereby pointing to a favourable saddle location inland of Kottasberge. Dynamic model runs during the glacial cycles are now needed to investigate the stability of the flow characteristics over the anticipated age of the core. Such model runs would also yield the pattern of elevation changes and could help with dating the core, both in the planning phase and after the drilling.

\section{ACKNOWLEDGEMENTS}

Many people have been very helpful by supplying data. We are particularly grateful to H. Oerter, M. van den Broeke, D. G. Vaughan, and M. B. Giovinetto for partly sharing unpublished datasets. We are also indebted to R. C. Warner and W. F. Budd for providing their computer code for calculating the balance flow. Financial support from the Fund for Scientific Research, Flanders, and the Belgian Impulse Programme on Global Change (Prime Minister's Office - Federal Office for Scientific, Technical and Cultural Affairs) is also gratefully acknowledged. This work is a contribution to the "European Project for Ice Coring in Antarctica" (EPICA), a joint European Science Foundation/European Commission (EG) scientific programme, funded by the EG under the Environment and Climate Programme (1994-1998), contract No. ENV4-CT95-0074, and by national contributions from Belgium, Denmark, France, Germany, Italy, The Netherlands, Norway, Sweden, Switzerland and the United Kingdom. This is EPICA publication No. 13 and AWI contribution No. 1689. The gridded datasets developed in this paper will be made available on request.

\section{REFERENGES}

Allison, I., N.W. Young and T. Medhurst. 1985. Correspondence. On re-assessment of the mass balance of the Lambert Glacier drainage basin, Antarctica. f. Glaciol., 31 (109), 378-381.

Bamber, J. L. and P. Huybrechts. 1996. Geometric boundary conditions for modelling the velocity field of the Antarctic ice sheet. Ann. Glaciol., 23, 364-373.

Bamber, J. L., R. J. Hardy, P. Huybrechts and I. Joughin. 2000. A comparison of balance, measured and thermomechanically modelled velocities for the Greenland ice sheet. Ann. Glaciol., 30 (see paper in this volume).

Barker, P. F., P. J. Barrett, A. K. Cooper and P. Huybrechts. 1999. Antarctic glacial history from numerical models and continental margin sediments. Palaeogeogr., Palaeoclimatol., Palaeoecol., 150, 247-267.

Budd, W. F. and R. C. Warner. 1996. A computer scheme for rapid calculations of balance-flux distributions. Ann. Glaciol., 23, 21-27.

Budd, W. F., D. Jenssen and I. N. Smith. 1984. A three-dimensional time-dependent model of the West Antarctic ice sheet. Ann. Glaciol., 5, 29-36.

Drewry, D. J., ed. 1983. Antarctica: glaciological and geophysical folio. Cambridge, University of Cambridge. Scott Polar Research Institute.

Drewry, D. J., S. R. Jordan and E. Jankowski. 1982. Measured properties of the Antarctic ice sheet: surface configuration, ice thickness, volume and bedrock characteristics. Ann. Glaciol., 3, 83-91.

Fox, A. J. and A. P. R. Cooper. 1994. Measured properties of the Antarctic ice sheet derived from the SCAR Antarctic digital database. Polar Rec., 30(174), 201-206.

Giovinetto, M. B. and C. R. Bentley. 1985. Surface balance in ice drainage systems of Antarctica. Antarct. F. U.S., $20(4), 6-13$.

Huybrechts, P. 1990. A 3-D model for the Antarctic ice sheet: a sensitivity study on the glacial-interglacial contrast. Climate Dyn., 5(2), 79-92.

Huybrechts, P. and J. de Wolde. 1999. The dynamic response of the Green- 
land and Antarctic ice sheets to multiple-century climatic warming. $f$ Climate, 12(8), 2169-2188.

Oerter, H., W. Graf, F. Wilhelms, A. Minikin and H. Miller. 1999. Accumulation studies on Amundsenisen, Dronning Maud Land, by means of tritium, DEP and stable isotope measurements: first results from the 1995/96 and 1996/97 field season. Ann. Glaciol., 29, 1-9.

Oerter, H. and 6 others. 2000. Accumulation rates in Dronning Maud Land, Antarctica, as revealed by dielectric-profiling measurements of shallow firn cores. Ann. Glaciol., 30 (see paper in this volume).

Robin, G. de Q. 1977. Ice cores and climatic change. Philos. Trans. R. Soc. London, Ser. B, 280(972), 143-168.

Siegert, M. J., J. A. Dowdeswell, M. R. Gorman and N. F. McIntyre. 1996. An inventory of Antarctic sub-glacial lakes. Antarct. Sci., 8(3), 281-286.

Smith, W. and P. Wessel. 1990. Gridding with continuous curvature splines in tension. Geophysics, 55(3), 293-305.

Steinhage, D., U. Nixdorf, U. Meyer and H. Miller. 1999. New maps of the ice thickness and subglacial topography in Dronning Maud Land, Antarctica, determined by means of airborne radio-echo sounding. Ann.
Glaciol., 29, 267-272.

Thomson, J.W. and A. P. R. Cooper. 1993. The SCAR Antarctic digital topographic database. Antarct. Sci., 5(3), 239-244.

Van den Broeke, M. R. and 6 others. 1999. Climate variables along a traverse line in Dronning Maud Land, East Antarctica. 7. Glaciol., 45(150), 295-302.

Vaughan, D. G. 1996. Report of the First BEDMAP Workshop on Antarctic Bed Mapping, 21-22 October 1996. Cambridge, British Antarctic Survey.

Vaughan, D.G. and 9 others. 1995. Subglacial and seabed topography, ice thickness and water column thickness in the vicinity of FilchnerRonne-Shelfeis, Antarctica. Polarforschung, 64(2), 1994, 75-88.

Vaughan, D. G., J. L. Bamber, M. B. Giovinetto, J. Russell and A. P. R. Cooper. 1999. Reassessment of net surface mass balance in Antarctica. 7. Climate, 12(4), 933-946.

Wilhelms, F., J. Kipfstuhl, H. Miller, K. Heinloth and J. Firestone. 1998. Precise dielectric profiling of ice cores: a new device with improved guarding and its theory. F. Glaciol., 44(146), 171-174.

Wingham, D. J., A. L. Ridout, R. Scharroo, R. J. Arthern and C. K. Shum. 1998. Antarctic elevation change 1992 to 1996. Science, 282(5388), 456-458. 